\title{
Vitamin A Measurement
}

National Cancer Institute

\section{Source}

National Cancer Institute. Vitamin A Measurement. NCI Thesaurus. Code C74895.

The determination of the amount of Vitamin A present in a sample. 